Cite this: DOI: $10.1039 / \mathrm{c3ra41404c}$

Received 21st March 2013,

Accepted 11th June 2013

DOI: $10.1039 / c 3 r a 41404 c$

www.rsc.org/advances

\title{
Glutathione-sensitive nanoplatform for monitored intracellular delivery and controlled release of Camptothecin $\dagger$
}

\author{
Carlos Muniesa, ${ }^{a}$ Víctor Vicente, ${ }^{\text {bc }}$ Manuel Quesada, ${ }^{a}$ Sara Sáez-Atiénzar, bc José \\ R. Blesa, ${ }^{\text {bc }}$ Ibane Abasolo, ${ }^{d}$ Yolanda Fernández ${ }^{d}$ and Pablo Botella*a
}

\begin{abstract}
We report the design, synthesis, characterization and in vitro testing of a novel nanodrug based on a covalent linking model that allows intracellular controlled release of the pharmaceutical payload. A new synthetic strategy is implemented by direct coupling of as-synthesized (pyridin-2-yldisulfanyl)alkyl carbonate derivatives of camptothecin (CPT) with thiol groups of silica hybrid nanoparticles containing a non-porous core and a mesoporous shell. Upon reaction with thiols in physiological conditions, disulfide bridge cleavage occurs, releasing the naked drug after an intramolecular cyclization mechanism. Additional incorporation of a fluorophore into particles core facilitates imaging at the subcellular level for the monitoring of uptake and delivery. Confocal microscopy experiments in HeLa cervix cancer cells confirms that nanoparticles enter the cells by endocytosis but are able to escape from endo-lysosomes and enter the cytosolic compartment to release their cargo. The incorporation to cells of L-buthioninesulfoximine, a glutathione inhibitor allows concluding that the intracellular releasing mechanism is mainly driven by the reducing activity of this tripeptide. This camptothecin nanoplatform shows the same cytotoxic activity than the free drug and is clearly superior to those release systems depending on enzymatic hydrolysis (as determined by calculation of the $\mathrm{IC}_{50}$ ratios).
\end{abstract}

\section{Introduction}

The administration of cytotoxic drugs, like antitumorals, constitutes a major challenge for the clinical practice. Very frequently, their poor pharmaceutical profile and serious undesired effects precludes their practical use in humans. ${ }^{1-3}$ In this sense, the delivery strategy in chemotherapy has been mostly focused on stimuli-responsive systems that promote controlled release of their payload inside the target cells. ${ }^{4-7}$ Here, redox-sensitive, disulfide-based mechanisms have shown significant efficiency for selective intracellular release,

\footnotetext{
${ }^{a}$ Instituto de Tecnología Química (UPV-CSIC), Av. Los Naranjos s/n, 46022 Valencia, Spain. E-mail: pbotella@itq.upv.es; Fax: (+34) 96-3879444; Tel: (+34) 96-3877819 ${ }^{b}$ Facultad de Medicina, Universidad Católica de Valencia "San Vicente Mártir", C/ Quevedo 2, 46001 Valencia, Spain

"Instituto Universitario de Investigación "Dr Viña Giner", Universidad Católica de Valencia "San Vicente Mártir", C/ Quevedo 2, 46001 Valencia, Spain

${ }^{d}$ CIBBIM-Nanomedicine and Networking Biomedical Research Center on Bioengineering, Biomaterials and Nanomedicine (CIBER-BBN), Vall d'Hebron Institut de Recerca, Hospital Universitari Vall d'Hebron, Universitat Autònoma de Barcelona, Passeig Vall d'Hebron 119-129, 08035 Barcelona, Spain

$\dagger$ Electronic supplementary information (ESI) available: General methods, synthesis of CPT prodrugs precursors, CPT prodrugs reports of RP-HPLC, ${ }^{1} \mathrm{H}$ NMR, ${ }^{13} \mathrm{C}-\mathrm{NMR}$, ESI-MS and Q-TOF, complete material structural and physicochemical characterization (DLS, powder XRD, BET, ${ }^{29} \mathrm{Si}$-MAS-NMR and ${ }^{13} \mathrm{C}-\mathrm{MAS}-$ NMR). Also, stability test of the nanodrug in cell uptake conditions, images of cell internalization and cytotoxicity controls are provided.
}

based mainly in glutathione-driven cleavage. ${ }^{8,9}$ Otherwise, mesoporous silica nanoparticles (MSN) have been proposed for the delivery and controlled release of small therapeutic molecules and for theranostic systems, due to their large surface area, tunable pore size, multifunctionality and good biocompatibility, ${ }^{10-13}$ and they look like good candidates as vehicles for the delivery of covalently linked anticancer compounds such as camptothecin and paclitaxel. ${ }^{14,15}$ Unfortunately, the direct coupling of these molecules to an inorganic nanoparticle is circumvented by the reduced therapeutic activity of the structure-modified derivatives. ${ }^{16}$ It would be desirable to develop covalent linking models that allow for the controllable release of the free drug after cell entry. ${ }^{17}$ Secondly, it is necessary to establish precisely when, where and how the pharmaceutical payload is released into the cells. To address these targets, we have developed a novel camptothecin nanoplatform based in a mercapto-functionalized silica hybrid containing a non-porous core and a mesoporous shell. A new synthetic strategy has been implemented by reacting novel (pyridin-2-yldisulfanyl)alkyl carbonate derivatives of camptothecin (CPT, a topoisomerase I inhibitor ${ }^{18,19}$ with thiol groups of the inorganic support. This allowed us to attach the drug over the pores of the external coating by a cleavable disulfide linker, sensitive to thiols such as glutathione (GSH) or dithiothreitol (DTT), which are able to 
release the naked molecule after an intramolecular cyclization mechanism. In vitro biological evaluation of this delivery platform has been done on a HeLa cervix cancer cell line. Furthermore, in order to state the mechanisms for cell uptake, internal trafficking and controlled release, we have incorporated a fluorophore (Rhodamine-B, RhB) into the core of the inorganic vehicle, facilitating imaging at the subcellular level.

\section{Experimental section}

All reagents and solvents were purchased from Sigma-Aldrich except HPLC solvents (HPLC grade from Scharlab or LC/MS grade Optima from Fisher).

HeLa cells were originally obtained from the American Type Culture Collection (Rockville, MD) maintained in RPMI media supplemented with $10 \%$ fetal bovine serum (FBS, from Lonza, Verviers, Belgium) at $37{ }^{\circ} \mathrm{C}$ under a humidified atmosphere of 95\% air and $5-10 \% \mathrm{CO}_{2}$.

\section{Synthesis of camptothecin prodrugs}

(Pyridin-2-yldisulfanyl)alkyl carbonate derivatives of CPT were synthesized according to Scheme 1 . The purity of all obtained molecules was determined by RP-HPLC and the chemical structure was confirmed by ${ }^{1} \mathrm{H}$ NMR, ${ }^{13} \mathrm{C}$ NMR and Q-TOF MS analysis (see supplementary information $\dagger$ ).

Compounds 2a-c were synthesized following procedures reported earlier. ${ }^{20}$ Briefly, to a solution of 2-aldrithiol $(4.71 \mathrm{~g}$, $21.4 \mathrm{mmol})$ in methanol purged with nitrogen $(20 \mathrm{~mL})$ was added dropwise 2-mercaptoethanol $(0.50 \mathrm{~mL}, 7.1 \mathrm{mmol})$, 3-mercaptopropanol $(0.61 \mathrm{~mL}, 7.1 \mathrm{mmol})$ or 4-mercapto-1butanol $(0.717 \mathrm{~mL}, 7.1 \mathrm{mmol})$ dropwise. The reaction was allowed to stir for $2 \mathrm{~h}$. The solvent was removed under reduced pressure. The yellow oil obtained was purified by flash chromatography using a mixture of DCM-methanol (95:5 v/ v) to afford the corresponding (pyridin-2-yldisulfanyl) alcohol: 2a (985 mg, 80\%, assay 85\%), 2b (931 mg, 64\%, assay 99\%) or 2c $(1.267 \mathrm{~g}, 83 \%$, assay $93.5 \%)$.

For the preparation of prodrugs $4 \mathbf{a}-\mathbf{c}$, different synthetic routes from literature have been appreciably modified. ${ }^{21-25}$ To a solution of DMAP $(225 \mathrm{mg}, 1.8 \mathrm{mmol})$ and CPT $(150 \mathrm{mg}, 0.43$ mmol) in anhydrous $\mathrm{CH}_{2} \mathrm{Cl}_{2}(30 \mathrm{~mL})$, triphosgene (66 mg, 0.24 mmol) was added at room temperature $(\mathbf{4 a})$ or at $0{ }^{\circ} \mathbf{C}(\mathbf{4 b}-\mathbf{c})$. After $15 \mathrm{~min}, \mathbf{2 a}-\mathbf{c}(0.7 \mathrm{mmol})$ was added. The solution was allowed to react at room temperature $(\mathbf{4 a})$ or $0{ }^{\circ} \mathrm{C}(\mathbf{4 b}-\mathbf{c})$ for 16 $\mathrm{h}(\mathbf{4 a - b})$ or $5 \mathrm{~h}(\mathbf{4 c})$ under an argon atmosphere. The reaction was quenched by washing with fresh water. The organic layer was washed with brine and dried using anhydrous $\mathrm{MgSO}_{4}$. The solvent was removed under reduced pressure. The yellowish

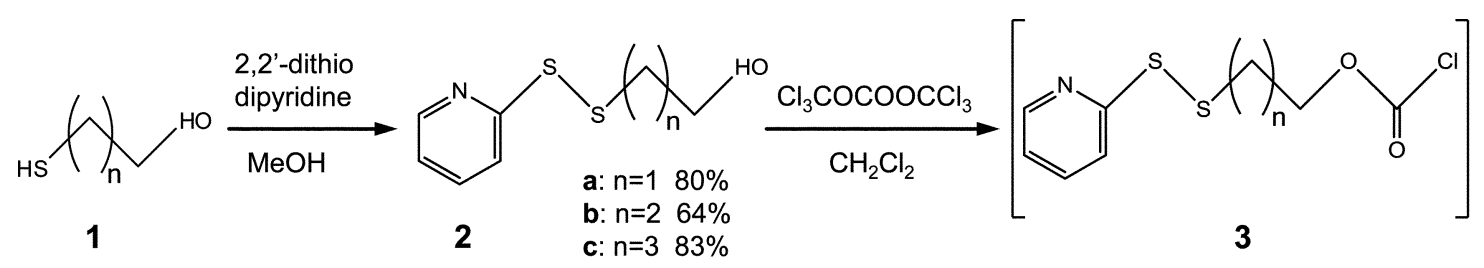

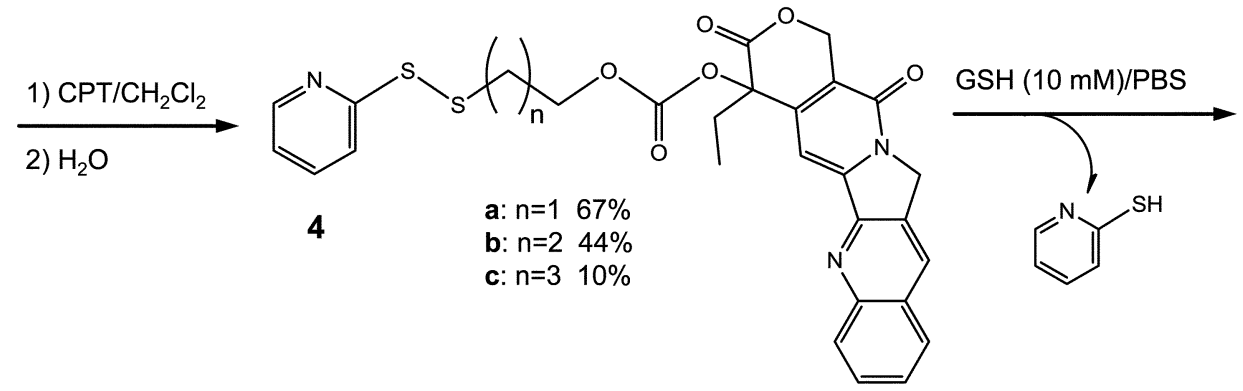<smiles>CCC1(OC(=O)COC(C)(C)C)C(=O)OCc2c1cc1n(c2=O)Cc2cc3ccccc3nc2-1</smiles>

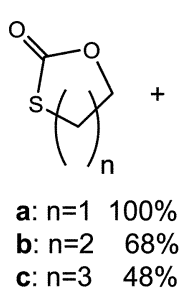<smiles>CCC1(O)C(=O)OCc2c1cc1n(c2=O)Cc2cc3ccccc3nc2-1</smiles> 
oil was dissolved in the minimum amount of hot methanol and stored at $4{ }^{\circ} \mathrm{C}$ for $48 \mathrm{~h}$. The off-white solid was filtered and washed with methanol and then dried under vacuum to yield the corresponding (pyridin-2-yldisulfanyl)alkyl carbonate camptothecin: 4a (165 mg, 67\%, assay 95\%), 4b (109 mg, $44 \%$, assay $90 \%)$ or 4 c (25 mg, $10 \%$, assay $70 \%)$.

\section{Synthesis of the CPT nanoplatform}

To a mixture of Triton-X100 (53 mL), hexanol $(54 \mathrm{~mL})$ and cyclohexane $(225 \mathrm{~mL})$ was added $2 \mathrm{~mL}$ of a TMR-APTES solution $\left(7 \mathrm{mg} \mathrm{mL}^{-1}\right),{ }^{26}$ water $(15 \mathrm{~mL})$ and $\mathrm{NH}_{4} \mathrm{OH}(3 \mathrm{~mL}, 30 \%$ $\mathrm{v} / \mathrm{v}$ ). The mixture was allowed to stir for $30 \mathrm{~min}$. Then, TEOS (3 $\mathrm{mL}$ ) was added and the reaction was allowed to stir for $24 \mathrm{~h}$. The fluorescent cores were isolated by centrifugation (30 000 g, $15 \mathrm{~min}$ ) and washed twice with ethanol and deionised water. These cores were suspended in ultra-pure water $(3 \mathrm{~mL})$ and mixed with a solution of CTAB $(100 \mathrm{~mL}, 8 \mathrm{mM})$ and $\mathrm{NaOH}(1$ $\mathrm{mL}, 100 \mathrm{~mm})$. Then, a TEOS solution in ethanol $(0.3 \mathrm{~mL}, 20 \%$ $\mathrm{v} / \mathrm{v}$ ) was added three times every $30 \mathrm{~min}$. The mixture was allowed to stir for $2 \mathrm{~h}$ at $60{ }^{\circ} \mathrm{C}$ and afterwards a solid was separated by centrifugation (12 $500 \mathrm{~g}, 15 \mathrm{~min}$ ) and washed with ethanol. Remaining in pores, CTAB was extracted for $20 \mathrm{~h}$ at $80{ }^{\circ} \mathrm{C}$ with $20 \mathrm{~mL}$ of a mixture of ethanol- $n$-heptane $(48: 52)$ containing $\mathrm{HCl} 0.15 \mathrm{M}$. The solid was again centrifuged (12 $500 \mathrm{~g}, 15 \mathrm{~min}$ ), washed with ethanol and freeze-dried. 170 $\mathrm{mg}$ of the core-shell nanoparticles (RhB-SiO $\left.{ }_{2} @ M S N\right)$ were dried under vacuum at $75{ }^{\circ} \mathrm{C}$ for $6 \mathrm{~h}$. Then, anhydrous toluene $(0.5 \mathrm{~mL})$ and MPTMS $(0.32 \mathrm{~mL})$ was added, and the mixture was stirred at $120{ }^{\circ} \mathrm{C}$ for $16 \mathrm{~h}$. Hybrid nanoparticles were filtered and washed with toluene and methanol. $100 \mathrm{mg}$ RhB$\mathrm{SiO}_{2} @ M S N-S H$ particles were suspended in DTT solution (10 $\mathrm{mL}, 100 \mathrm{mM}$ ) and stirred for $30 \mathrm{~min}$. Then, the suspension was centrifuged (12 $500 \mathrm{~g}, 15 \mathrm{~min}$ ) and the solid obtained was washed with methanol. Afterwards, 4a solution $(3.3 \mathrm{~mL}$ in DMSO, $\left.10 \mathrm{mg} \mathrm{mL}^{-1}\right)$ and methanol (16 mL) was added, and the mixture was stirred for $16 \mathrm{~h}$. Then, the suspension was centrifuged (12 $500 \mathrm{~g}, 15 \mathrm{~min}$ ) and the obtained solid (RhB$\mathrm{SiO}_{2}$ @MSN-SS-CPT) was washed with methanol repeatedly until no rest of $4 \mathbf{a}$ or CPT was detected by UV-Vis $\left(\mathrm{A}_{368}\right)$, and was freeze-dried.

\section{Materials characterization}

Powder X-ray diffraction patterns (XRD) were collected using a Philips X'Pert diffractometer equipped with a graphite monochromator, operating at $40 \mathrm{kV}$ and $45 \mathrm{~mA}$ and employing nickel-filtered $\mathrm{Cu}-\mathrm{K} \alpha$ radiation $(\lambda=0.1542 \mathrm{~nm})$. Nitrogen gas adsorption isotherms were measured in a Micromeritics Flowsorb apparatus. Surface area calculations were carried out using the BET method, whereas pore size distribution was calculated according to the Kruk-Jaroniec-Sayari estimation. ${ }^{27}$ The nanoparticles' morphology was studied by transmission electron microscopy (TEM) in a Philips CM-10 microscope operating at $100 \mathrm{kV}$. Samples were dispersed in methylchloride and transferred to carbon coated copper grids. Particle size and $Z$-potential measurements were conducted by diffuse light scattering (DLS), using a Zetasizer Nano ZS (Malvern Instruments Ltd., Worcestershire, United Kingdom). Dried materials were re-suspended in deionized water at a concentration of $5 \mu \mathrm{g} \mathrm{mL} \mathrm{L}^{-1}$ and DLS measurements were performed at $25{ }^{\circ} \mathrm{C}$ and $173^{\circ}$ scattering angle. The mean hydrodynamic diameter was determined by cumulant analysis. Magic angle spinning-nuclear magnetic resonance (MAS-NMR) spectra were recorded at room temperature under magic angle spinning (MAS) on a Bruker AV400 spectrometer, with a 7 mm Bruker BL-7 probe at sample spinning rate of $5 \mathrm{kHz}$. The single pulse ${ }^{29} \mathrm{Si}$ spectra were acquired using pulses of $3.5 \mu \mathrm{s}$ corresponding to a flip angle of $3 \pi / 4 \mathrm{rad}$ and a recycle delay of $240 \mathrm{~s}$, and referred to tetramethylsilane (TMS). The ${ }^{1} \mathrm{H}$ to ${ }^{13} \mathrm{C}$ cross-polarization spectra were acquired by using a 90 pulse for ${ }^{1} \mathrm{H}$ of $5 \mu \mathrm{s}$, a contact time of $5 \mathrm{~ms}$ and a recycle of $3 \mathrm{~s}$, and referred to adamantine. Diffuse-reflectance (DR) UV-vis spectra were collected on a Cary 5 equipped with a 'Praying Mantis' attachment from Harric.

\section{Redox-sensitive release of CPT}

To evaluate the release of CPT from conjugates $4 a-c, 950 \mu \mathrm{L}$ PBS and $50 \mu \mathrm{L}$ of a prodrug solution $\left(5 \mathrm{mg} \mathrm{mL}^{-1}\right)$ were mixed in a $1.5 \mathrm{~mL}$ eppendorf tube. Then, $3.1 \mathrm{mg}$ GSH was added to the solution to reach a $10 \mathrm{mM}$ reducing agent concentration and the tube was placed at a Thermomixer $\mathbb{R}$ equipment at 37 ${ }^{\circ} \mathrm{C}$ and $1350 \mathrm{rpm}$. After $24 \mathrm{~h}$ the sample was freeze-dried and further dissolved with $950 \mu \mathrm{L}$ methanol and $50 \mu \mathrm{L} \mathrm{HCl} 1 \mathrm{M}$ solution. This sample was analyzed by RP-HPLC and ESI-MS.

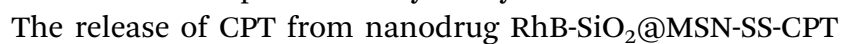
was monitored by placing $5 \mathrm{mg}$ material in a vial with $1 \mathrm{~mL}$ PBS solution. The tube was vigorously shaken using a vortex for $30 \mathrm{~s}$. Then the suspension was placed in a Thermomixer $\mathbb{R}$ at $37{ }^{\circ} \mathrm{C}$ and $1350 \mathrm{rpm}$. After $2 \mathrm{~h}, 3.1 \mathrm{mg} \mathrm{GSH}$ was added to the solution to reach $10 \mathrm{mM}$ concentration of reducing agent. At the corresponding time the sample was centrifuged (12 500 g, $15 \mathrm{~min}$ ) and the supernatant was freeze-dried and further dissolved with $950 \mu \mathrm{L}$ methanol and $50 \mu \mathrm{L} \mathrm{HCl} 1 \mathrm{M}$ solution. This sample was analyzed by RP-HPLC and ESI-MS. Triplicate samples were run for every experiment.

\section{Cytotoxicity study}

HeLa cells (4000 cells per well, 96-well plates) were seeded and stabilized for $48 \mathrm{~h}$ in RPMI supplemented with $10 \%$ fetal bovine serum (FBS) and 1\% antibiotic (Streptomycin/ Penicillin) at $37{ }^{\circ} \mathrm{C}$ in $95 \%$ air and $5 \% \mathrm{CO}_{2}$ environment. After incubation, growth medium was exchanged before further additions. Then, cells with fresh medium were treated with CPT loaded nanocarrier, 4a compound (in DMSO) or CPT (in DMSO), with final doses ranging from 0.025 to $2.5 \mu \mathrm{g} \mathrm{mL}$ (in CPT equivalents). After $72 \mathrm{~h}$, MTT solution in PBS was added at a final concentration of $0.2 \mathrm{mg} \mathrm{mL}^{-1}$ to the wells and $4 \mathrm{~h}$ later formazan crystals were dissolved in DMSO and spectrophotometrically measured at $550 \mathrm{~nm}$ (Perkin-Elmer VictorX5 Microplate Reader). IC $_{50}$ calculation survival data were evaluated by variable slope curve-fitting using Prism 5.0 software (GraphPad, San Diego, CA). Three independent experiments were performed for every sample, and each experiment was carried out with five points per concentration.

\section{Cell internalization and intracellular CPT release}

$10 \mu \mathrm{g} \mathrm{mL}^{-1}$ in CPT equivalents of RhB-SiO ${ }_{2} @ M S N-S S-C P T$ was incubated for $24 \mathrm{~h}$ with HeLa cells. After washing excess nanoparticles with sterile PBS, cells were incubated for $15 \mathrm{~min}$ 
with $10 \mu \mathrm{M}$ Lysotracker Green (Invitrogen), fixed with 4\% paraformaldehyde and mounted with Prolong $\mathbb{R}$ (Invitrogen) mounting media. Internalization of labeled nanoparticles was analyzed by confocal microscopy (Olympus FV1000 Confocal and Spectral Microscope) using excitation peaks at 488/561 nm and emission at 522/585 $\mathrm{nm}$ for Lysotracker and RhB, respectively. Images were acquired at $60 \times$ magnification at every $\mu \mathrm{m}$, with an optical resolution of about $800 \mathrm{~nm}$.

Intracellular CPT release was estimated by seeding HeLa cells in p10 plates (3000 cells per plate) containing RPMI supplemented with 10\% FBS. After $24 \mathrm{~h}$, growth medium was exchanged and cells were incubated with $20 \mathrm{nM}$ in CPT equivalents of RhB-SiO ${ }_{2}$ @MSN-SS-CPT. After 24, 48 and $72 \mathrm{~h}$, cells were washed with PBS, trypsinized and lysed by sonication. Intracellular contents collected after centrifugation $(500 \mu \mathrm{L})$ were treated with $5 \%$ TCA aqueous solution at $4{ }^{\circ} \mathrm{C}$ $(500 \mu \mathrm{L})$. The protein precipitate was removed by centrifugation (9000 g, $10 \mathrm{~min}, 4{ }^{\circ} \mathrm{C}$ ), and the supernatant was freezedried and further dissolved with $950 \mu \mathrm{L}$ methanol and $50 \mu \mathrm{L}$ $\mathrm{HCl} 1 \mathrm{M}$ solution. Then, the released CPT was determined by RP-HPLC and ESI-MS. Triplicate samples were run for every experiment.

\section{Inhibition of intracellular CPT release}

HeLa cells (4000 cells per well, 96-well plates) were seeded and stabilized for $24 \mathrm{~h}$ in RPMI supplemented with $10 \%$ fetal bovine serum (FBS) at $37{ }^{\circ} \mathrm{C}$ in $95 \%$ air and $5 \% \mathrm{CO}_{2}$ environment. Next, L-buthionine sulfoximine (BSO, 0-1 mM) or chloroquine (CLQ, $0.15 \mathrm{mM}$ ) was added, and cells were incubated for a further $24 \mathrm{~h}$. After incubation, growth medium was exchanged and cells with fresh medium were treated with RhB-SiO ${ }_{2} @ M S N-S S-C P T$ or CPT (in DMSO), with final doses ranging from 0.025 to $2.5 \mu \mathrm{g} \mathrm{mL}^{-1}$ (in CPT equivalents). After $72 \mathrm{~h}, \mathrm{IC}_{50}$ calculation survival data were evaluated as described above. Three independent experiments were performed for every sample, and each experiment was carried out with five points per concentration.

\section{Results and discussion}

\section{Synthesis of prodrugs and CPT nanoplatform}

A major obstacle in implementing our aim was the synthetic difficulty of coupling a disulfide-derivative of CPT to an inorganic support. While prodrugs of CPT with cleavable disulfide linkers that release the unaltered drug have been developed, no information was available on its direct attachment to a nanoparticulated transporter. ${ }^{21-25}$ We therefore performed a singular synthetic strategy based on the direct incorporation of CPT prodrugs on the nanocarrier. For this purpose, we first synthesized novel (pyridin-2-yldisulfanyl)alkyl carbonate derivatives of CPT, according to Scheme 1 (compounds $\mathbf{4 a - c}$ ). These elaborated systems were thus expected to release CPT upon disulfide cleavage by GSH.

All compounds were characterized by ${ }^{1} \mathrm{H}$ NMR, ${ }^{13} \mathrm{C}$ NMR and Q-TOF analysis (see Supplementary† Fig. S1-S4).

The sensitivity to reducing agents of the conjugates $\mathbf{4 a - c}$ was assayed by measuring (RP-HPLC and ESI-MS) their decom- position when incubated $24 \mathrm{~h}$ at $37{ }^{\circ} \mathrm{C}$ in phosphate buffered saline (PBS, 1x, pH 7.4) with $10 \mathrm{mM}$ GSH. Disulfide cleavage took place in $1 \mathrm{~h}$ in all cases (Scheme 1). However, the desired following intramolecular cyclization and cleavage of the neighboring carbonate bond of 5a-c to yield free $\mathrm{CPT}, \mathrm{CO}_{2}$ and the corresponding thiolactone only happened quantitatively for the 5a compound. Conversely, carbonate $\mathbf{5 b}$ released only $68 \%$ CPT and 5c showed less than $50 \%$ of the therapeutic molecule. This pattern of stability of the carbonate derivative correlates to the increasing distance between the carbonyl group and the proximal sulfur atom, and agrees strongly with the behavior observed for similar disulfide conjugates of luciferin. $^{20}$

Although all three conjugates were sufficiently stable for coupling to mercapto-functionalized silica nanoparticles, only the most sensitive carbonate to reducing agents was selected to react with surface thiol groups. First, nonporous silica cores doped with $\mathrm{RhB}$ were synthesized by co-condensation of tetramethylrhodamine B isothiocyanate (TRITC) modified with 3-aminopropyltriethoxysilane (APTES) to form TMR-APTMS ${ }^{26}$ with tetraethyl orthosilicate (TEOS) and then, a mesoporous silica wall was grown by silicate polymerization in the presence of the cationic cetyltrimethylammonium bromide (CTAB) and further removal of the organic template with ethanol. ${ }^{28}$ The obtained core-shell nanoparticles were reacted with (3mercaptopropyl)trimethoxysilane (MPTMS) to produce RhB$\mathrm{SiO}_{2} @ M S N-S H$. Subsequently, 4a was covalently coupled with the inorganic support by disulfide bond, as shown in Fig. 1.

Particles with a diameter of around 50-60 nm, a non-porous core and a wormhole-like mesoporous shell (BET area $=139.4$ $\mathrm{m}^{2} \mathrm{~g}^{-1}$, pore diameter $=34 \AA$ ) were synthesized (Fig. 2a). It is noticeable that, although rarely, some particle dimers and trimers were also found in TEM images, due to simultaneous growth of the mesoporous silica wall of several nanoparticles together (see supplementary information $\dagger$ Fig. S5). Zeta potential measurements confirmed stable colloids in aqueous medium with negative charge on surface $(\zeta=-17.0 \pm 6.6 \mathrm{mV})$. Nevertheless, some polydispersion was observed by DLS (PI = 0.152 , average hydrodynamic diameter $=91 \pm 35 \mathrm{~nm}$, volume output), probably corresponding to the small quantity of nanoparticles dimmers and trimmers detected by electronic microscopy. ${ }^{29}$ Diffuse reflectance UV-vis spectroscopy of RhB$\mathrm{SiO}_{2} @ M S N-S S-C P T$ showed broad absorption bands at $368 \mathrm{~nm}$ (CPT) and $560 \mathrm{~nm}$ (RhB, Fig. 2b). The loading of these molecules was $4.7 \%$ of the dye (as determined by elemental analysis) and $3.5 \%$ of the drug (as measured by RP-HPLC after release, see below). Material structural and physico-chemical characterization was completed by powder XRD and MAS-NMR (see supplementary information † Fig. S6-S10 and Table S1).

In order to investigate the drug release behavior of RhB$\mathrm{SiO}_{2} @ M S N-S S-C P T, G S H 10 \mathrm{mM}$ was used as an external stimulus to trigger the redox-responsive mechanism, as this compound is the major small molecule reducing agent in the cytoplasm. Former non-specific release in PBS of $0-2 \%$ was observed within $2 \mathrm{~h}$ at $37{ }^{\circ} \mathrm{C}$ by RP-HPLC and ESI-MS, indicating a good stability of the linker system (Fig. 3). Then, addition of GSH for disulfide bond cleavage led to a burst initial release of CPT (about 40\% in $3 \mathrm{~h}$ ) followed by a slower release that was completed after $72 \mathrm{~h}(>95 \%$ after $48 \mathrm{~h})$. We 

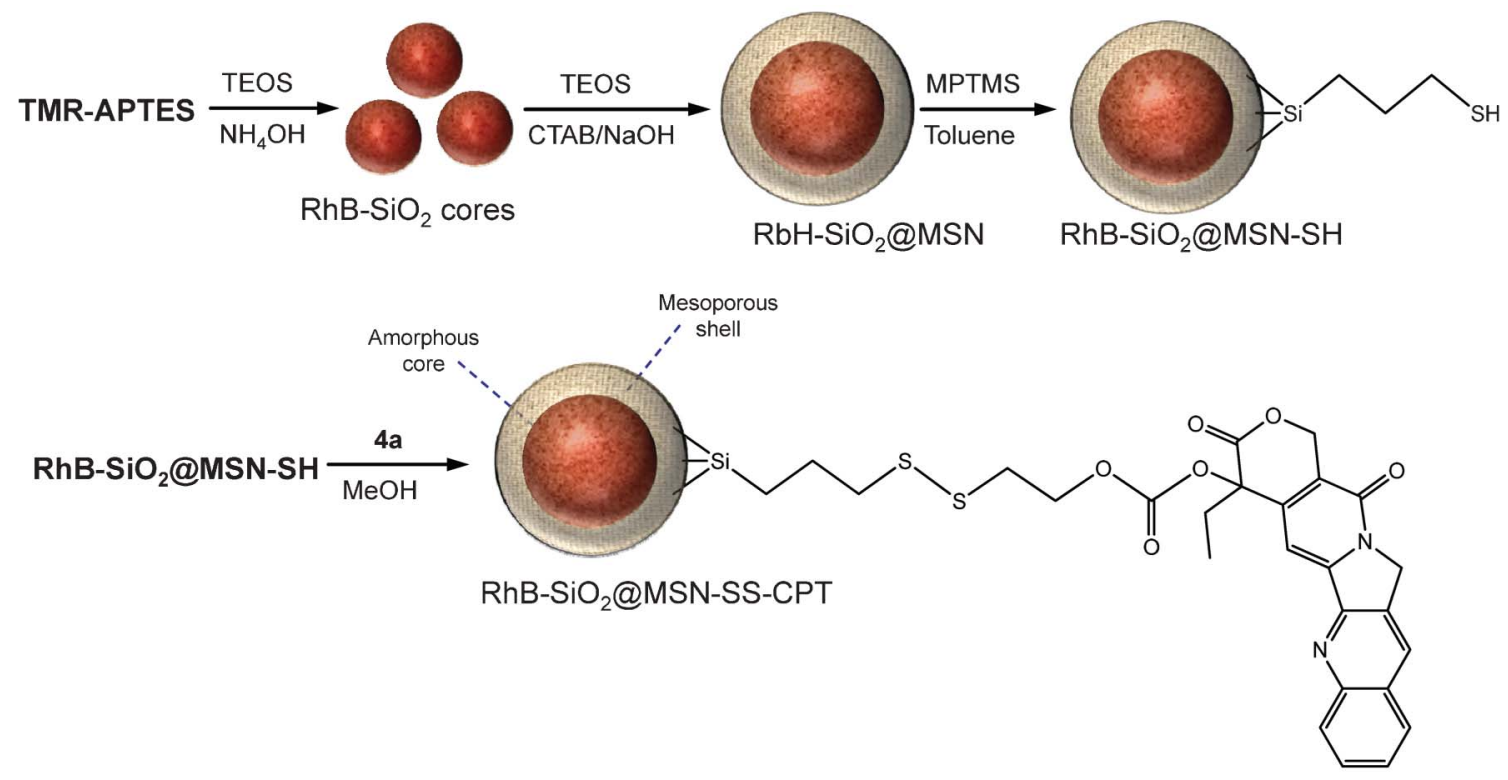

Fig. 1 Preparation of the novel therapeutic redox-responsive nanoplatform.

are aware that some intermediate compounds as $\mathbf{5 a}$ and mixed disulfides of GSH with the prodrug could be formed during this process. However, under our analytical conditions none of these intermediates was detected. Therefore, we assume that such a slow release of CPT is due to the lower GSH concentration and its moderate reduction potential. ${ }^{30}$ In fact, the system was much more sensitive to a stronger thiolreducing molecule like DTT (see supplementary information $†$ Fig. S11).

In any case, this novel nanoplatform showed high resistance to hydrolysis in cell uptake experimental conditions, as we detected only about $8 \%$ of CPT released after $24 \mathrm{~h}$ incubation in conditioned cell culture medium (RPMI supplemented with $10 \%$ FBS after $24 \mathrm{~h}$ contact with HeLa cells, see Fig. S12 in Supplementary Information†). Furthermore, we know that following endocytosis the particles are likely to be exposed to low $\mathrm{pH}$ at the endo-lysosomal compartments that could trigger the premature release of the drug molecule (before reaching the cytosol). In order to check this, we incubated the nanoparticle in an acid buffer solution ( $\mathrm{pH}$ 5.5) for $24 \mathrm{~h}$. The results (Fig. S12, ESI $\dagger$ ) show that the carbonate-disulfide linking system is consistently resistant to proton concentration in endocytic vacuoles.
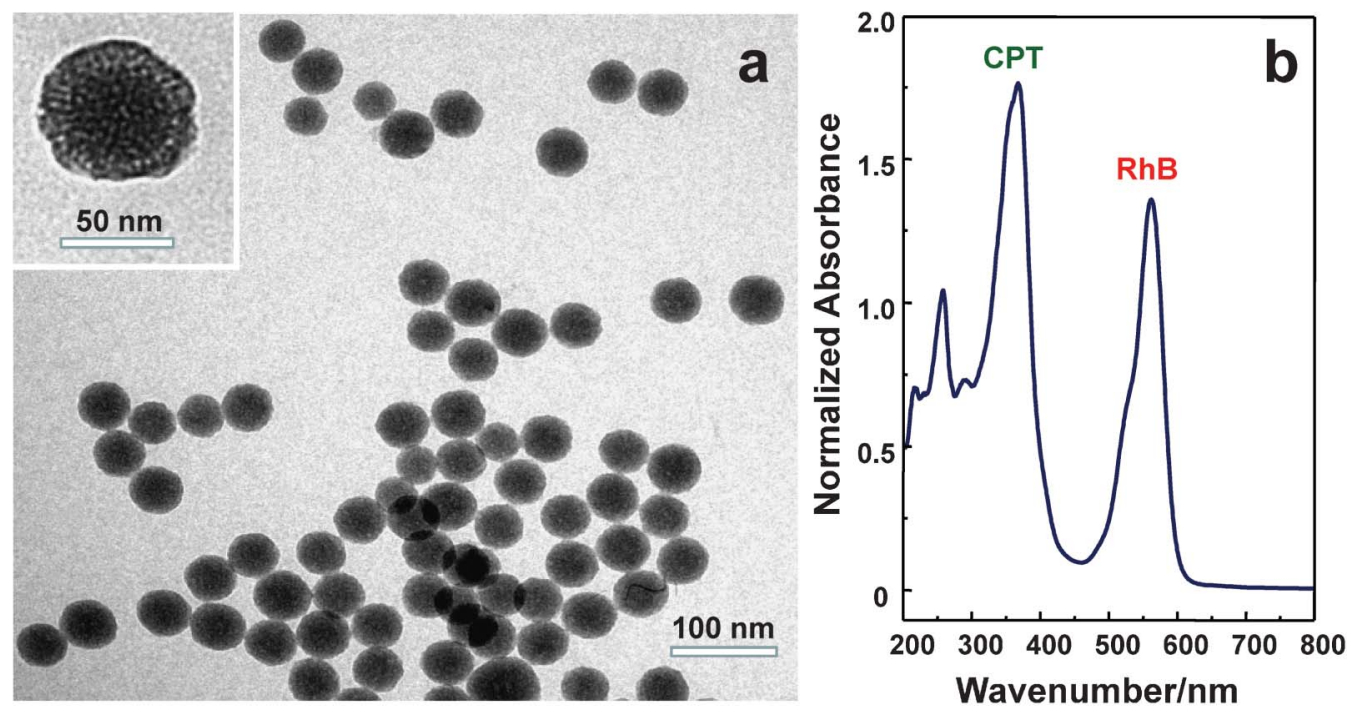

Fig. 2 Redox-responsive RhB-SiO ${ }_{2} @ M S N-S S-C P T$ nanoparticles. (a) TEM images. Core-shell morphology is clearly appreciated in the inset. (b) Diffuse reflectance UVvis spectrum showing bands corresponding to CPT (368 nm) and RhB (560 nm). 

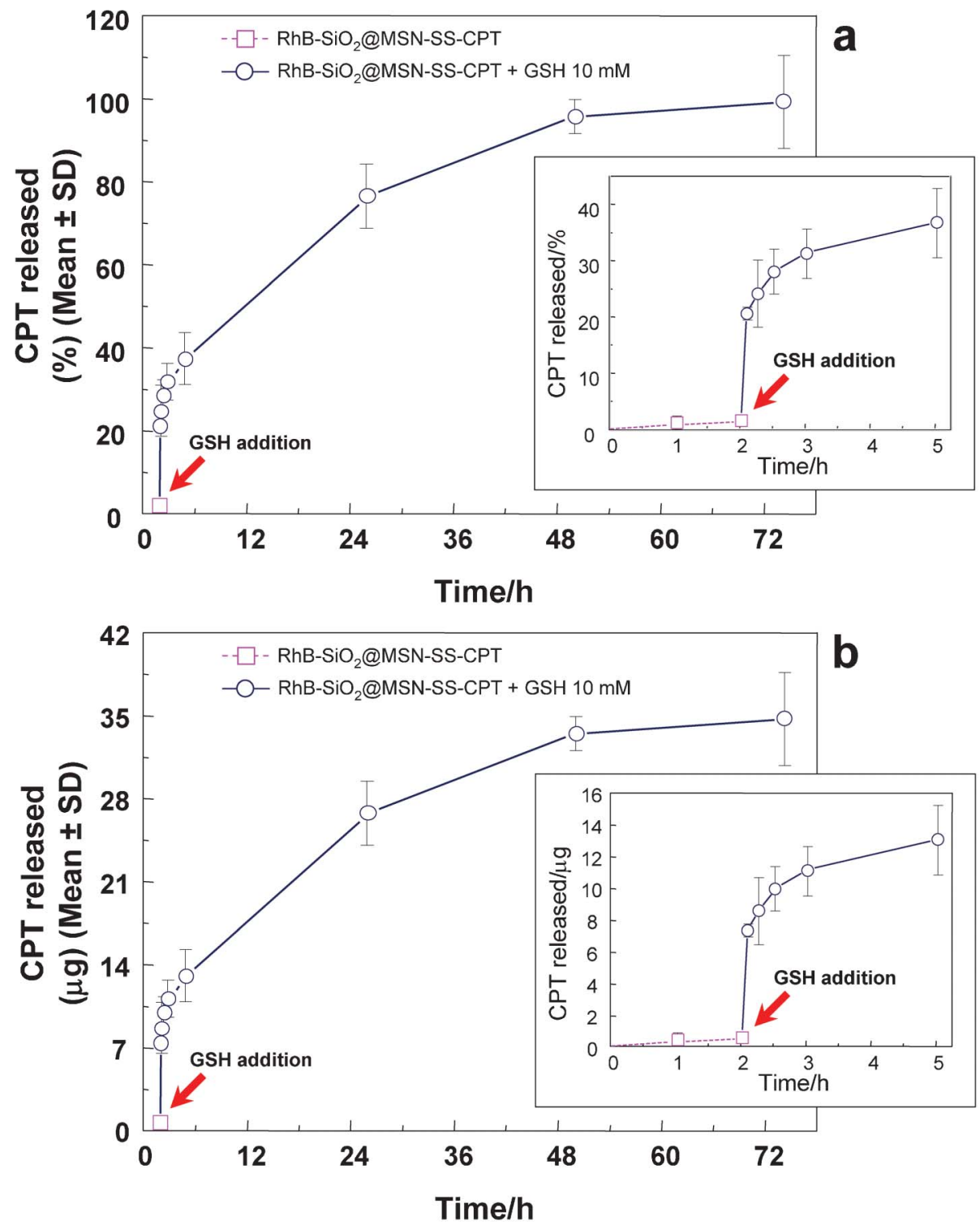

Fig. 3 Cumulative release profile of CPT at $37{ }^{\circ} \mathrm{C}$ from RhB-SiO ${ }_{2} @ M S N-S S-C P T$ in PBS after addition of GSH (10 mM). (a) Percentage of released drug. (b) Mass of released drug. In both cases the inset shows the previous non-specific release of CPT in PBS after incubation for $2 \mathrm{~h}$.

\section{Cytotoxicity and intracellular location}

Cell uptake experiments were conducted by incubating during $72 \mathrm{~h}$ HeLa cancer cells with different concentrations of RhB$\mathrm{SiO}_{2} @ M S N-S S-C P T\left(0.0025 \mu \mathrm{g} \mathrm{mL}^{-1}\right.$ to $2.5 \mu \mathrm{g} \mathrm{mL}^{-1}$ in CPT equivalents). Such a long incubation time was stated due to the observed drug release pattern with GSH and the specific cytotoxicity mechanism of CPT. The sub-micron size of nanoparticles and the negative surface charge would probably favor clathrin mediated internalization of the conjugate inside HeLa cells via endocytosis pathway, in agreement with recent research pointed out by different authors for MSN. ${ }^{31-35}$ The cytotoxic efficacy of the CPT delivery was studied by MTT viability assay and compared to the efficacy of molecule $\mathbf{4 a}$ and the pure drug (Fig. 4). The internalized particles were visually observed by confocal laser scanning microscopy (CLSM). Both the CPT loaded nanocarrier and free CPT presented very similar value of half maximal inhibitory concentration $\left(\mathrm{IC}_{50}\right)$, which is consistent with previous results comparing the activity of CPT-loaded nanoparticles with CPT dissolved in DMSO. ${ }^{31}$ However, due to its strongly hydrophobic character, the prodrug molecule showed limited solubility in RPMI media, even when incorporating it as a DMSO solution. This hinders the uptake by cells and seriously reduces its efficacy. Moreover, due to this insolubility, we assume that the obtained cell viability curve for the 4 a compound is a rough estimation and its cytotoxic activity can't be accurately compared. On the other hand, we are aware that some materials like single wall carbon nanotubes can absorb MTTformazan crystallites, leading to overestimation of their real cytotoxic activity. ${ }^{36}$ However, it is worth noting that nonloaded RhB-SiO ${ }_{2} @ M S N-S H$ nanoparticles present scarce cyto- 

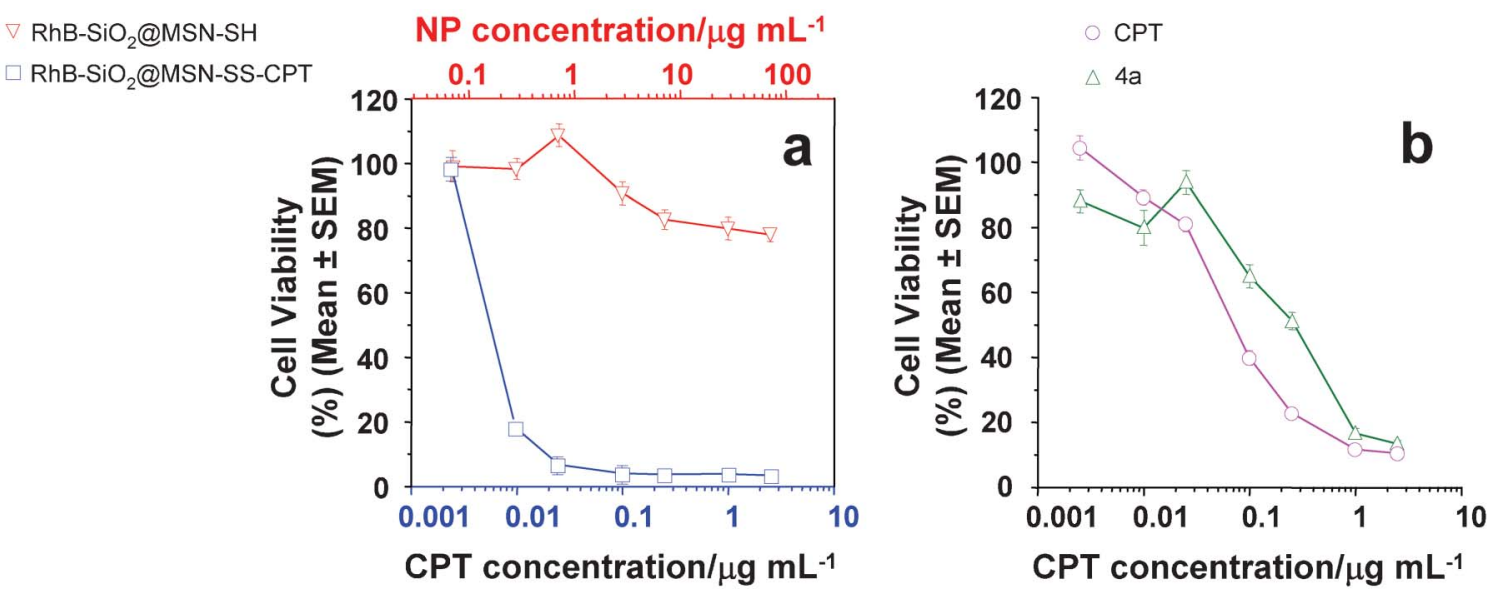

Fig. 4 In vitro MTT cell viability assays in HeLa cell line. (a) RhB-SiO ${ }_{2} @ M S N-S S-C P T$ and non-loaded RhB-SiO $2 @ M S N-S H$. (b) CPT and compound 4a. All samples were incubated for 72 h. Top X-axis indicates the concentration of RhB-SiO ${ }_{2} @ M S H-S H$ calculated on the base of CPT-loaded nanocarrier.

toxicity at the range of concentrations tested (about $80 \%$ cell viability at maximum particle loading in Fig. 4a). Furthermore, when incubating CPT with corresponding quantities of RhB$\mathrm{SiO}_{2} @ \mathrm{MSN}-\mathrm{SH}$ nanoparticles, there is no significant change in the $\mathrm{IC}_{50}$ pattern of the free drug (see Fig. S12 and Table S2 in the supplementary informationt). Consequently, we can say that in this case mesoporous silica nanoparticles are not interfering MTT-formazan determination and the obtained cytotoxicity data are good estimations.

To investigate successful cell entry and intracellular location of RhB-SiO ${ }_{2} @ M S N-S S-C P T$ co-localization experiments were conducted by incubating HeLa cells with particles. Previously, it must be taken into account that during incubation in RPMI supplemented with FBS (10\%) nanoparticles are coated by a protein corona, which can modify the surface charge and then the process of cellular uptake. ${ }^{35,37}$ For this reason, $Z$-potential was determined after $24 \mathrm{~h}$ incubation in cell culture medium. Results show that $Z$-potential remains negative after protein coating, although its value decreases substantially $(\zeta=-9.7 \pm$ 0.8 ), which should favor nanoparticles entering into cells through the endocytic pathway. ${ }^{37}$ In fact, we have found significant nanoparticle internalization by analyzing confocal images acquired at different heights along the $Z$-axis after $24 \mathrm{~h}$ incubation. These show nanoparticles co-localizing with lysosomes (Fig. 5a-c).

Interestingly, at this incubation time, nanoparticles can also be seen outside lysosomes (Fig. 5d-f and Fig. S14 in the supplementary information†), which means that the nanoparticles are able to shift into cytosol. Here, recent research points to endosomal escape as a bottle-neck for stimuli-responsive models based on redox-driven intracellular disulfide cleavage. ${ }^{38}$ However, the negative surface charge of RhB$\mathrm{SiO}_{2} @ M S N-S S-C P T$, even after coating by the protein corona), can promote the escape of nanoparticles from endo-lysosomal compartments and enter the cytosol to release their cargo. ${ }^{39}$ Overall, these observations indicate that nanoparticles were able to deliver CPT to the cell cytoplasm by entering cells via endocytosis and later on escaping the endo-lysosomal compartment.

\section{CPT intracellular release mechanism}

Despite the demonstrated cytoplasmatic location of nanoparticles, the internal release mechanism of most disulfide-based delivery systems is still to be proven. Although most of the delivery systems based in disulfide bonds are designed for intracellular bioreduction, it must also be considered that bioreduction can also take place in the extracellular space ${ }^{40-42}$ due to the action of cell-surface oxido-reductases (for example, protein disulfide isomerase, PDI) and/or chaperones (also PDI). ${ }^{42}$ In fact, we found some hydrolysis of the disulfide linker and CPT release when incubating nanoparticles with conditioned cell culture medium. To clarify this, we tried to determine the release efficiency of CPT from nanocarriers in the cells. For this purpose, we incubated HeLa cells with 20

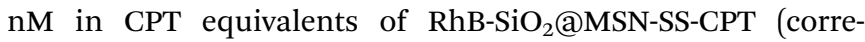
sponding to $0.007 \mu \mathrm{g} \mathrm{mL}^{-1}$ of $\mathrm{CPT}$, the $\mathrm{IC}_{50}$ ) for $24-72 \mathrm{~h}$. After incubation, survivor cells were lysed by sonication and, after centrifugation, CPT was determined in the cytosolic solutions. The results (Fig. 6) show a significant presence of released CPT in the cytoplasm that increases from 0 to $48 \mathrm{~h}$, suggesting the drug is being released after cell internalization.

Then, if we take into account the reasonable stability shown by $\mathrm{RhB}-\mathrm{SiO}_{2} @ \mathrm{MSN}$-SS-CPT in cell uptake experiments, the subcellular localization of nanoparticles found in the CLSM images, and the observed increase of CPT cytosolic levels with incubation time, we can claim that the mechanism of disulfide exchange occurs to a large extent within the cell.

Here, while some authors point out the role of GSH for disulfide cleavage and cytosolic release, ${ }^{8,9,17,21-25,43-46}$ the endosomal/lysosomal reducing activity mediated by $\mathrm{PDI}^{43}$ or endosomal reductase,${ }^{47}$ could also bring an early download of the therapeutic molecule. In addition, it must be taken into account that carbonate bonds could also be cleaved by unspecific cytosolic carboxylases. ${ }^{24}$ To provide further evidence of the suggested GSH-driven mechanism of CPT release the cytotoxic activity of $\mathrm{RhB}^{-\mathrm{SiO}_{2} @ M S N-S S-C P T}$ was studied by MTT assay in the presence of a GSH synthesis inhibitor like BSO.$^{48}$ BSO was added to a concentration range of $0.1-1 \mathrm{mM}$ 

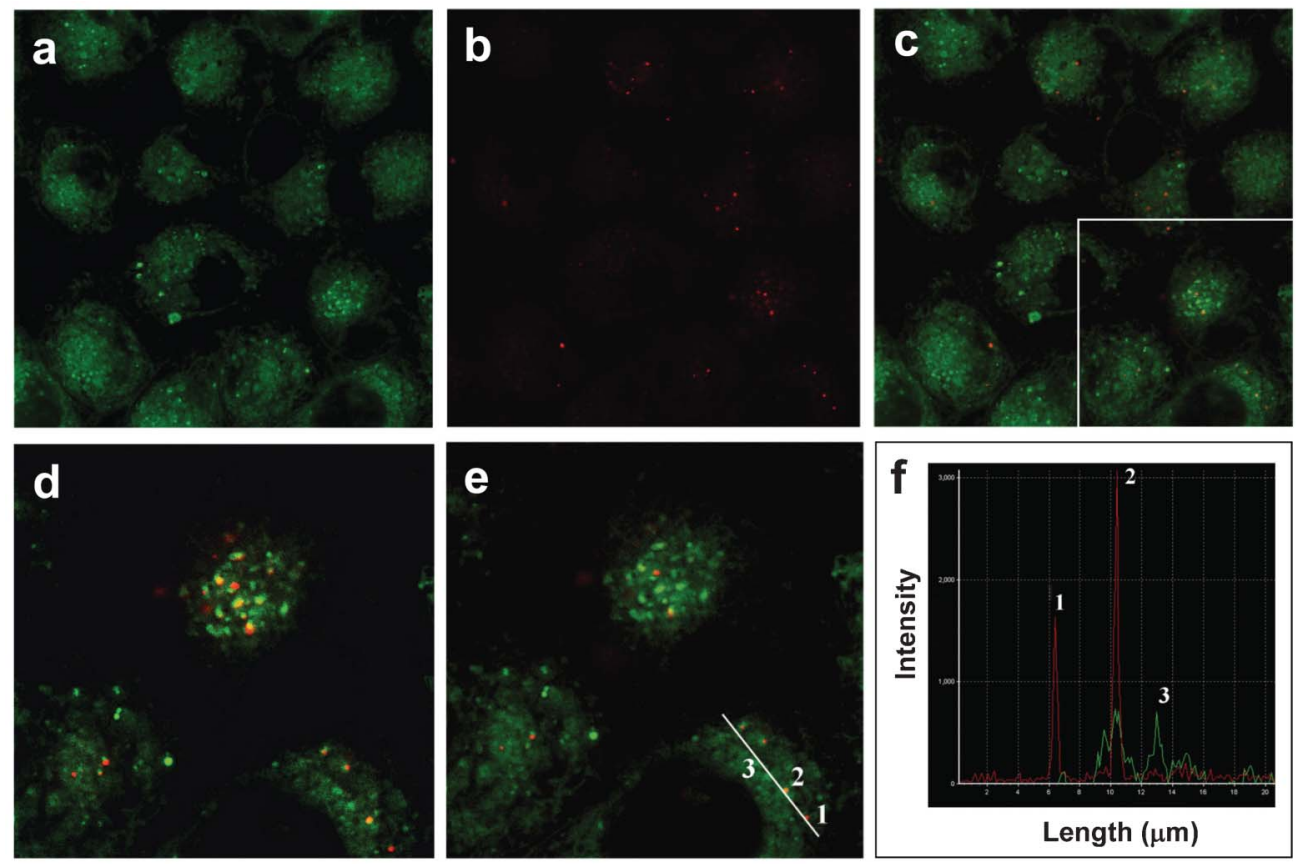

Fig. 5 Co-localization studies of RhB-SiO $@$ @MSN-SS-CPT in HeLa cells. Confocal images of the same $Z$ plane were obtained for (a) Lysotracker and for (b) Rhodamine B-labeled nanoparticles, and (c) merged afterwards to demonstrate that some of the nanoparticles are allocated inside acidic organelles labeled by Lysotracker. (d) Inset in c. (e) Same image as in d with higher background-threshold for green signal. White row indicates the line depicted for (f) signal intensity plot. Numbers correspond to nanoparticles in the cytosol (1), nanoparticles colocalizing with lysosomes (2) and lysosomes without nanoparticles (3).

$24 \mathrm{~h}$ before $\mathrm{RhB}-\mathrm{SiO}_{2} @ \mathrm{MSN}-\mathrm{SS}-\mathrm{CPT}$ incorporation to deplete GSH levels in HeLa cells. Maximum cell resistance to the antitumor drug due to GSH inhibition is found for $0.1 \mathrm{mM}$ BSO in the cell culture, $\left(\mathrm{IC}_{50}\right.$ value triplicates the experiment with no BSO, Fig. 7 and Table 1). The effect is particularly strong at low dose range (green zone in Fig. 7a). Further BSO additions, however, lead to a decrease of $\mathrm{IC}_{50}$, due to the intrinsic cytotoxicity observed for BSO concentrations above $0.5 \mathrm{mM}$ (see Fig. S15 in supplementary information†). We have also discarded the possibility that GSH depletion could cause

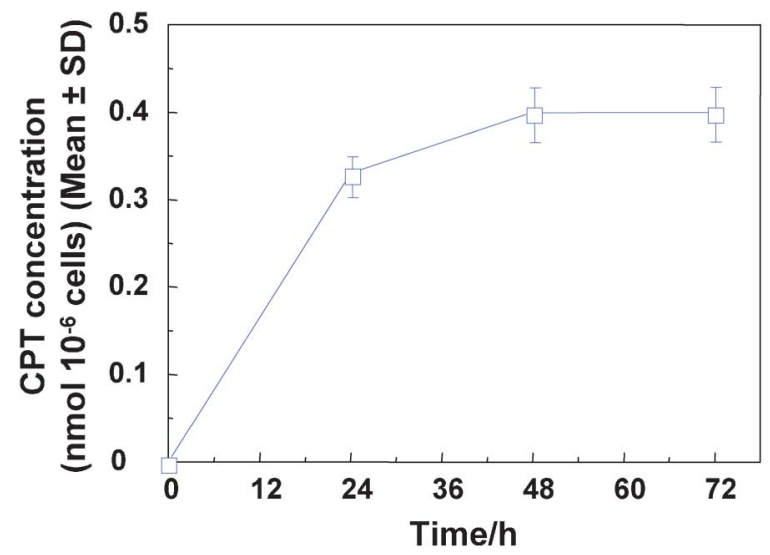

Fig. 6 Cumulative release profile of CPT from RhB-SiO ${ }_{2} @ M S N-S S-C P T$ in cytosolic solutions obtained after incubating HeLa cells with RhB-SiO $2 @ M S N-S S-$ CPT (20 nm in CPT equivalents) for 24-72 h, and further cell lysis by sonication. changes in the activity of the CPT, as a control with CPT and BSO $0.1 \mathrm{mM}$ showed no significant change over the solely CPT test (Fig. S16 and Table S3 in supplementary informationt).

As an additional control, we have carried out a MTT test with RhB-SiO $\mathrm{O}_{2} @ \mathrm{MSN}-\mathrm{SS}-\mathrm{CPT}$ and introducing CLQ, an aminoquinoline drug that produces severe depletion of GSH levels. ${ }^{49}$ CLQ $(0.15 \mathrm{mM})$ was added $24 \mathrm{~h}$ before CPT-loaded nanoparticles, Results (Fig. S17 and Table S4 in supplementary information†) show a very powerful inhibition effect on the nanodrug cytotoxicity, with $\mathrm{IC}_{50}$ becoming four times the experiment with no inhibitor).

All together, these findings support the role of GSH in the activation of the intramolecular cyclization that commands drug release. Nevertheless, we assume that other mechanisms, mostly referred above, could also be involved in the CPT intracellular discharge.

\section{Disulfide vs. ester linkage for CPT intracellular delivery}

We have recently published the first silica-based nanocarrier for delivery of covalently coupled CPT. ${ }^{14}$ An ester bond, sensitive to cytoplasmatic carboxylases provided a slow release mechanism of the drug but with lower efficiency than the naked drug, due to sterical restrictions that affect the enzymatic hydrolysis of the ester linker and prevent a complete releasing process. ${ }^{50,51}$ Conversely, since thiol species, including GSH are more abundant in tumor cells than in normal cells, MSN-containing disulfide-based delivery systems are expected to release completely the delivered therapeutic payload upon exposure to thiols. ${ }^{45,52-55}$ Consistently with this

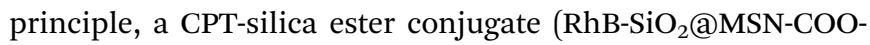



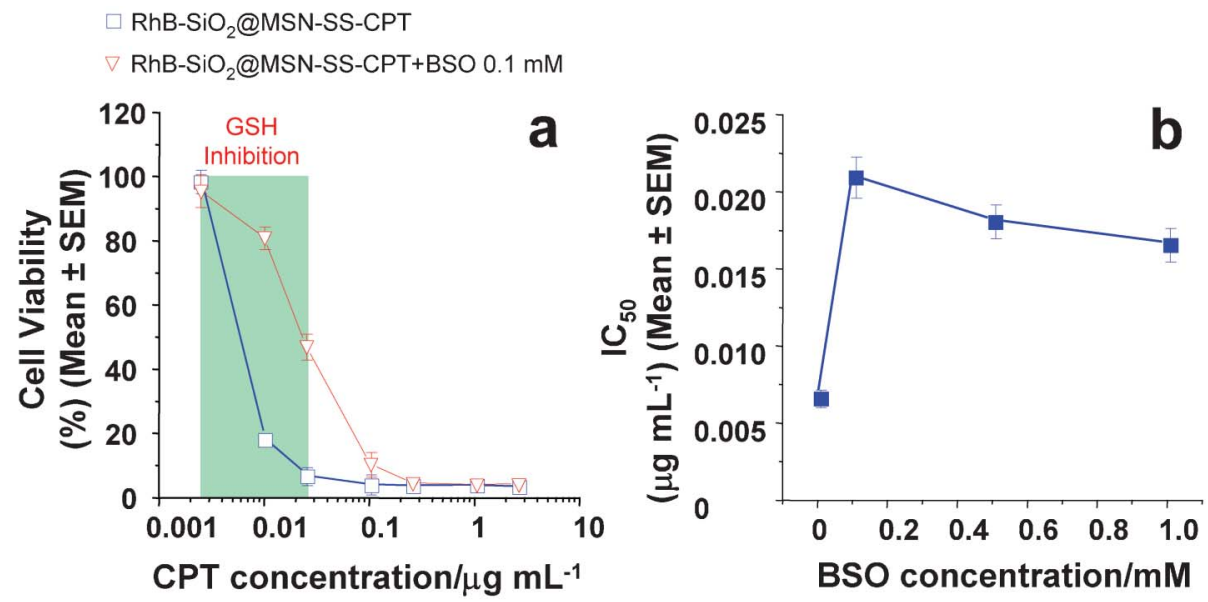

Fig. 7 Inhibition of intracellular CPT release with BSO in HeLa cell line as stated by in vitro MTT cell viability assay. (a) Effect of BSO $0.1 \mathrm{mM}$ in cytotoxic activity of RhB$\mathrm{SiO}_{2} @ \mathrm{MSN}-\mathrm{SS}-\mathrm{CPT}$. The green zone corresponds to the range of CPT concentrations where the strongest inhibition episode happens. (b) Evolution of IC $\mathrm{C}_{50}$ value for RhB-SiO ${ }_{2} @ M S N-S S-C P T$ with the concentration of BSO

CPT) with equivalent drug content showed a significant higher $\mathrm{IC}_{50}$ value than $\mathrm{RhB}-\mathrm{SiO}_{2} @ M S N-S S-C P T$ (Table 1, Fig. 8).

The suggested cell uptake process and drug release mechanism of $\mathrm{RhB}^{-\mathrm{SiO}_{2} @ M S N-S S-C P T}$ is summarized in Scheme 2. Based on this delivery profile, we hypothesize that by modifying the length of the C-chain in the disulfide linker

Table $1 \mathrm{IC}_{50}$ values for tested samples in HeLa cells

\begin{tabular}{ll}
\hline Entry & $\mathrm{IC}_{50}{ }^{a}$ \\
\hline CPT & $0.0064 \pm 0.0007$ \\
4a & $0.1862 \pm 0.0225$ \\
RhB-SiO $@$ @MSN-SS-CPT & $0.0067 \pm 0.0005$ \\
RhB-SiO $@$ @MSN-SS-CPT + BSO 0.1 mM & $0.0211 \pm 0.0013$ \\
RhB-SiO 2 @MSN-COO-CPT & $0.0842 \pm 0.0164$
\end{tabular}

${ }^{a} \mathrm{CPT}$ concentration $\left(\mu \mathrm{g} \mathrm{mL}^{-1}\right)$. Data indicate the mean $\pm \mathrm{SEM}(\mu \mathrm{g}$ $\mathrm{mL}^{-1}$ ) of 3 experiments.

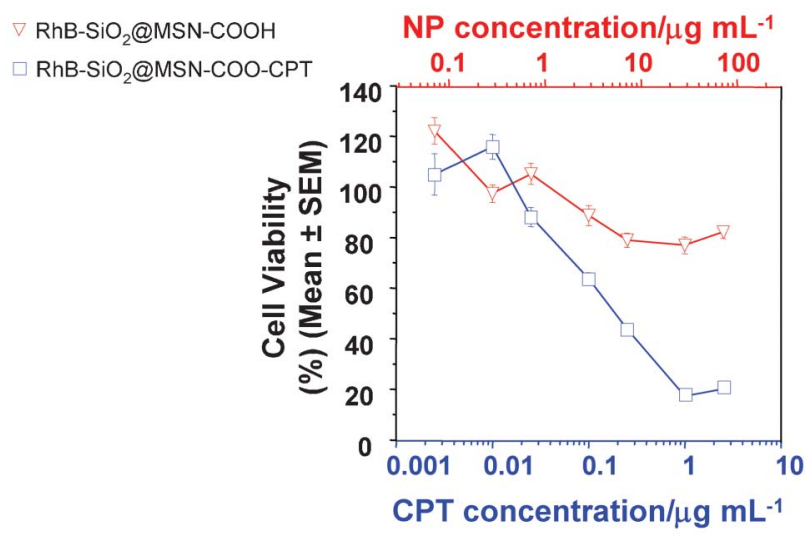

Fig. 8 In vitro MTT cell viability assay of the CPT-silica ester conjugate RhB$\mathrm{SiO}_{2} @ \mathrm{MSN}-\mathrm{COO}-\mathrm{CPT}$ and non-loaded RhB-SiO $2 @ \mathrm{MSN}-\mathrm{COOH}$. Top $X$-axis indicates the concentration of $\mathrm{RhB}-\mathrm{SiO}_{2} @ \mathrm{MSH}-\mathrm{COOH}$ calculated on the base of CPT-loaded nanocarrier. (e.g., by incorporation of compounds $\mathbf{4 b}$ or $\mathbf{4 c}$ ) this novel therapeutic system can introduce additional control over intracellular drug release.

\section{Conclusion}

We have developed a novel nanoparticulated core-shell system combining therapeutic activity and imaging at the subcellular level, based in an external covalent coupling model with a
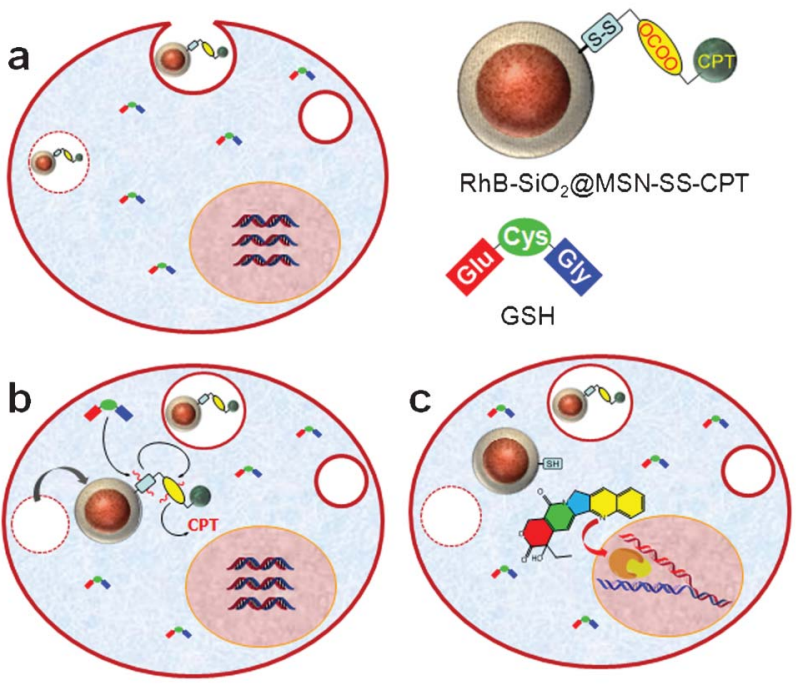

Scheme 2 Artistic representation of cell uptake process and drug release mechanism of RhB-SiO ${ }_{2} @ M S N-S S-C P T$ in HeLa cells. (a) Cell internalization by endocytic pathway of the multifunctional nanoparticles and co-localization in endo-lysosomes. (b) Escape of nanoparticles from endo-lysosomal compartments to the cytosol and activation of the redox-responsive linking system by GSH-driven disulfide reduction and further intermolecular cyclization, resulting in the release of free CPT and the corresponding thiolactone. (c) Entrance of CPT into the cell nucleus and inhibition of topoisomerase I during DNA replication. 
cleavable disulfide linker able to release the naked drug by means of an intramolecular cyclization mechanism and an internal fluorophore. For this purpose, a new synthetic strategy has been implemented by direct incorporation of CPT prodrugs on the nanocarrier. The negative surface charge of this system allows nanoparticles to escape from endolysosomes and enter the cytosol where the disulfide bridge can be reduced by a GSH-driven mechanism that provides controlled release of the drug with identical cytotoxic activity to the naked drug. The valuable stability provided in physiological medium points to an optimized delivery system able to surpass extracellular and intracellular barriers in order to monitor a fine control over releasable species.

\section{Acknowledgements}

This work was financially supported by "Comisión Interministerial de Ciencia y Tecnología" of Spain (projects CSD2009-00050 and MAT2012-39290-C02-02), and grants from CIBER-BBN (NanoMets Intramural Grant) "Fondo de Investigaciones Sanitarias - Instituto de Salud Carlos III" (PI080771) y "Universidad Católica de Valencia San Vicente Mártir” (PI2011-011-010). CM thanks the Spanish "Ministerio de Economía y Competitividad" for a FPU Ph.D. studentship (AP2008-02851). SSA thanks the "Universidad Católica de Valencia San Vicente Mártir” for a Ph.D. studentship.

\section{Notes and references}

1 T. Elbayouni and V. Torchilin, Nanomedicine in Health and Disease, Science Publishers Inc., Enfield, NH, 2011.

2 Y. Cao and R. Langer, Sci. Transl. Med., 2010, 2, 15 ps3.

3 I. Ojima, Pure Appl. Chem., 2011, 83, 1685.

4 W. Gao, J. M. Chan and O. C. Farokhzad, Mol. Pharmaceutics, 2010, 7, 1913.

5 L. E. Strong and J. L. West, Wiley Interdiscip. Rev.: Nanomed. Nanobiotechnol., 2011, 3, 307.

6 S. Ganta, H. Devalapally, A. Shahiwala and M. Amiji, J. Controlled Release, 2008, 126, 187.

7 R. V. Ulijn, J. Mater. Chem., 2006, 16, 2217.

8 R. Cheng, F. Feng, F. Meng, C. Deng, J. Feijen and Z. Zhong, J. Controlled Release, 2011, 152, 2.

9 G. Saito, J. A. Swanson and K.-D. Lee, Adv. Drug Delivery Rev., 2003, 55, 199.

10 J. M. Rosenholm, C. Sahlgren and M. Linden, Nanoscale, 2010, 2, 1870.

11 I. I. Slowing, J. L. Vivero-Escoto, C. W. Wu and V. S. Lin, Adv. Drug Delivery Rev., 2008, 60, 1278.

12 Z. Li, J. C. Barnes, A. Bosoy, J. F. Stoddart and J. I. Zink, Chem. Soc. Rev., 2012, 41, 2590.

13 H. Qianjun and J. Shi, J. Mater. Chem., 2011, 21, 5845.

14 P. Botella, I. Abasolo, Y. Fernández, C. Muniesa, S. Miranda, M. Quesada, J. Ruiz, S. Schwartz Jr and A. Corma, J. Controlled Release, 2011, 156, 246.

15 L. Tang, T. M. Fan, L. B. Borst and J. Cheng, ACS Nano, 2012, 6, 3954.

16 M. L. Rothenberg, Ann. Oncol., 1997, 8, 837.
17 J. Chen, S. Chen, X. Zhao, L. V. Kuznesova, S. S. Wong and I. Ojima, J. Am. Chem. Soc., 2008, 130, 16778.

18 J. Thompson, C. F. Stewart and P. J. Houghton, Biochim. Biophys. Acta, Gene Struct. Expression, 1998, 1400, 301.

19 V. J. Venditto and E. E. Simanek, Mol. Pharmaceutics, 2010, 7, 307.

20 L. R. Jones, E. A. Goun, R. Shinde, J. B. Rothbard, C. H. Contag and P. A. Wender, J. Am. Chem. Soc., 2006, 128, 6526.

21 M. H. Lee, J. Y. Kim, J. H. Han, S. Bhuniya, J. L. Sessler, C. Kang and J. S. Kim, J. Am. Chem. Soc., 2012, 134, 1316.

22 X.-Q. Li, H.-Y. Wen, H.-Q. Dong, W.-M. Xue, G. M. Pauletti, X.-J. Cai, W.-J. Xia, D. Shi and Y.-Y. Li, Chem. Commun., 2011, 47, 8647.

23 H. Cabral, M. Nakanishi, M. Kumagai, W.-D. Jang, N. Nishiyama and K. Kataoka, Pharm. Res., 2009, 26, 82.

24 W. A. Henne, D. D. Doorneweerd, A. R. Hilgenbrink, S. A. Kularatne and P. S. Low, Bioorg. Med. Chem. Lett., 2006, 16, 5350 .

25 A. Satyam, Bioorg. Med. Chem. Lett., 2008, 18, 3196.

26 D. Ma, A. J. Kell, S. Tan, Z. J. Jakubek and B. Simard, J. Phys. Chem. C, 2009, 113, 15974.

27 M. Kruk, M. Jaroniec and A. Sayari, Langmuir, 1997, 13, 6267.

28 R. Zhang, C. Wu, L. Tong, B. Tang and Q.-H. Xu, Langmuir, 2009, 25, 10153.

29 In the light scattering area, the polydispersity index (PI) is a parameter calculated from a Cumulants analysis of the DLS measured intensity autocorrelation function. The PDI is dimensionless and scaled such that values smaller than 0.05 are rarely seen other than with standards. The maximum value is arbitrarily limited to 1.0. A PDI value of 1 indicates that the sample has a very broad size distribution and may contain large particles or aggregates that could be slowly sedimenting.

30 C. S. Sevier and C. A. Kaiser, Nat. Rev. Mol. Cell Biol., 2002, 3, 836.

31 J. Lu, M. Liong, J. I. Zink and F. Tamanoi, Small, 2007, 3, 1341.

32 Q. He, Z. Zhang, Y. Gao, J. Shi and Y. Li, Small, 2009, 5, 2722.

33 J. M. Rosenholm, E. Peuhu, J. E. Eriksson, C. Sahlgren and M. Linden, Nano Lett., 2009, 9, 3308.

34 Z. Tao, B. B. Toms, J. Goodisman and T. Asefa, Chem. Res. Toxicol., 2009, 22, 1869.

35 Y.-P. Chen, H.-A. Chen, Y. Hung, F.-C. Chien, P. Chen and C.-Y. Mou, RSC Adv., 2012, 2, 968.

36 J. M. Wörle-Knirsch, K. Pulskamp and H. F. Krug, Nano Lett., 2006, 6, 1261.

37 E. Casals and V. F. Puntes, Nanomedicine, 2012, 7, 1917.

38 A. M. Sauer, A. Schlossbauer, N. Ruthardt, V. Cauda, T. Bein and C. Bräuchle, Nano Lett., 2010, 10, 3684.

39 I. Slowing, B. G. Trewyn and V. S.-Y. Lin, J. Am. Chem. Soc., 2006, 128, 14792.

40 E. P. Feener, W.-C. Shene and H. J.-P. Ryser, J. Biol. Chem., 1990, 265, 18780.

41 W. Sun and P. B. Davis, J. Controlled Release, 2010, 146, 118.

42 L. Brülisauer, N. Kathriner, M. Prenrecaj, M. A. Gauthier and J.-C. Leroux, Angew. Chem., Int. Ed., 2012, 51, 12454.

43 Y.-C. Wang, F. Wang, T.-M. Sun and J. Wang, Bioconjugate Chem., 2011, 22, 1939. 
44 A. N. Koo, H. J. Lee, S. E. Kim, J. H. Chang, C. Park, C. Kim, J. H. Park and S. C. Lee, Chem. Commun., 2008, 6570.

45 H. Kim, S. Kim, C. Park, H. Lee, H. J. Park and C. Kim, Adv. Mater., 2010, 22, 4280.

46 L. Yuan, W. Chen, J. Hu, J. Z. Zhang and D. Yang, Langmuir, 2013, 29, 734.

47 J. Yang, H. Chen, I. R. Vlahov, J.-X. Cheng and P. S. Low, Proc. Natl. Acad. Sci. U. S. A., 2006, 103, 13872.

48 G. K. Balendiran, R. Dabur and D. Fraser, Cell Biochem. Funct., 2004, 22, 343.

49 H. Ginsburg, O. Famin, J. Zhang and M. Krugliak, Biochem. Pharmacol., 1998, 56, 1305.

50 J. Cheng, K. T. Khin, G. S. Jensen, A. Liu and M. E. Davis, Bioconjugate Chem., 2003, 14, 1007.
51 K. H. Min, K. Park, Y. S. Kim, S. M. Bae, S. Lee, H. G. Jo, R. W. Park, I. S. Kim, S. Y. Jeong, K. Kim and I. C. Kwon, J. Controlled Release, 2008, 127, 208.

52 R. Guo, L.-L. Li, W.-H. Zhao, Y.-X. Chen, X.-Z. Wang, C.J. Fang, W. Feng, T.-L. Zhang, X. Ma, M. Lu, S.-Q. Peng and C.-H. Yan, Nanoscale, 2012, 4, 3577.

53 Z. Luo, K. Cai, Y. Hu, J. Li, X. Ding, B. Zhang, D. Xu, W. Yang and P. Liu, Adv. Mater., 2012, 24, 431.

54 Z. Luo, K. Cai, Y. Hu, L. Zhao, P. Liu, L. Duan and W. Yang, Angew. Chem., Int. Ed., 2011, 50, 640.

55 R. Mortera, J. Vivero-Escoto, I. I. Slowing, E. Garrone, B. Onida and V. S.-Y. Lin, Chem. Commun., 2009, 3219. 